\title{
The effect of insulin on expression of genes and biochemical pathways in human skeletal muscle
}

\author{
Xuxia Wu · Jelai Wang Xiangqin Cui - Lidia Maianu - Brian Rhees · \\ James Rosinski - W. Venus So - Steven M. Willi · Michael V. Osier • \\ Helliner S. Hill · Grier P. Page · David B. Allison · Mitchell Martin · \\ W. Timothy Garvey
}

Published online: 12 January 2008

(C) Humana Press Inc. 2008

\section{Erratum to: Endocrine (2007) 31(1):5-17 \\ DOI 10.1007/s12020-007-0007-x}

Owing to a website limitation, both the table cited on pp. 10-11 (Supplementary Table 1) and the table referred

Electronic supplementary material The online version of this article (doi:10.1007/s12020-008-9033-6) contains supplementary material, which is available to authorized users.

The online version of the original article can be found under doi:10.1007/s12020-007-0007-x.

X. Wu $(\bowtie) \cdot$ L. Maianu · H. S. Hill · W. T. Garvey Department of Nutrition Science, University of Alabama at Birmingham, 1675 University Boulevard, Birmingham, AL 35294-3360, USA

e-mail: xuxiawu@uab.edu

\section{Wu · H. S. Hill - D. B. Allison - W. T. Garvey} Clinicial Nutrition Research Unit, University of Alabama at Birmingham, Birmingham, AL 35294-3360, USA

J. Wang - X. Cui - G. P. Page - D. B. Allison Department of Biostatistics, University of Alabama at Birmingham, Birmingham, AL 35294, USA

B. Rhees · J. Rosinski $\cdot$ W. V. So $\cdot$ M. Martin

Department of researvh Informatics, Genetics and Genomics, Preclinical Research and Development, Hoffmann-La Roche, Inc, Nutley, NJ 07110, USA

S. M. Willi

Department of Pediatrics, university of Pennsylvania, Philadelphia, PA, USA to on p. 16 regarding the Rome et al. study, ref. 48, are reprinted here for completeness.

M. V. Osier

Department of Biological Sciences, Rochester Institute of

Technology, 85 Lomb Memorial Drive, Rochester, NY 14623, USA

W. T. Garvey

Birmingham Veterans Affairs Medical Center, Birmingham, AL 35233, USA 